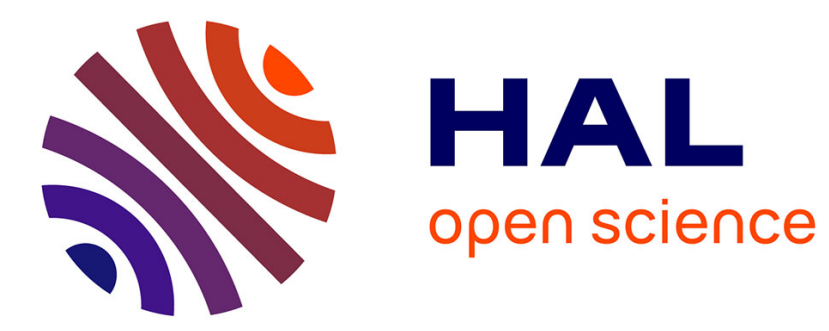

\title{
Memorias de la represión: infancias devastadas y autoficción
}

José García-Romeu

\section{To cite this version:}

José García-Romeu. Memorias de la represión: infancias devastadas y autoficción. Amerika - Mémoires, identités, territoires, 2016, 10.4000/amerika.7690 . hal-03586422

\section{HAL Id: hal-03586422 \\ https://hal.science/hal-03586422}

Submitted on 23 Feb 2022

HAL is a multi-disciplinary open access archive for the deposit and dissemination of scientific research documents, whether they are published or not. The documents may come from teaching and research institutions in France or abroad, or from public or private research centers.
L'archive ouverte pluridisciplinaire HAL, est destinée au dépôt et à la diffusion de documents scientifiques de niveau recherche, publiés ou non, émanant des établissements d'enseignement et de recherche français ou étrangers, des laboratoires publics ou privés. 
Amerika $\begin{aligned} & \text { Amerika } \\ & \text { Mémoires, identités, territoires }\end{aligned}$

$15 \mid 2016$

Coup d'état en Argentine et Guerre des Malouines

\section{Memorias de la represión: infancias devastadas y autoficción}

José García-Romeu

\section{Q OpenEdition}

Journals

Edición electrónica

URL: https://journals.openedition.org/amerika/7690

DOI: 10.4000/amerika.7690

ISSN: 2107-0806

Editor

LIRA-Université de Rennes 2

Este documento es traído a usted por Université de Toulon

\section{UNIVERSITÉ}

DE TOULON

Referencia electrónica

José García-Romeu, «Memorias de la represión: infancias devastadas y autoficción», Amerika [En

línea], 15 | 2016, Publicado el 15 diciembre 2016, consultado el 23 febrero 2022. URL: http:// journals.openedition.org/amerika/7690 ; DOI: https://doi.org/10.4000/amerika.7690

Este documento fue generado automáticamente el 29 septiembre 2020.

(c) Tous droits réservés 


\title{
Memorias de la represión: infancias devastadas y autoficción
}

\author{
José García-Romeu
}

Il restera toujours un survivant pour raconter

l'histoire. (Hannah Arendt, p. 1243)

1 La irrupción de la generación de H.I.J.O.S y la distancia cronológica cada vez mayor con los hechos históricos van generado en Argentina nuevas representaciones estéticas de la dictadura. Se han multiplicado así los relatos de infancia, asignados a narradores adultos, que adoptan la retrospectiva memorial para indagar los años de plomo. A propósito de $L a$ casa operativa de Cristina Feijóo, Patricio Lennard escribía en 2007 :

2 En los últimos diez años, una nueva serie de relatos y testimonios sobre la década del '70 ha ido adquiriendo espesor en la Argentina : la de los hijos de las víctimas del terrorismo de Estado. Un discurso generacional que irrumpe con el surgimiento de la agrupación HIJOS, a mediados de los '90, y que revela tanto el deseo de éstos por conocer el pasado de sus padres como una voluntad por construir una memoria propia [...].

En 2013, Karen Saban opinaba :

[...] en Argentina hay una generación de testigos directos del pasado que está pronta a morir [...]. Sin embargo, paralelamente, aparece un nuevo grupo de escritores en el paisaje literario, el de los "hijos de la memoria" ; ya sean hijos de desaparecidos o adultos jóvenes contemporáneos, quienes hasta el presente no habían protagonizado los discursos en torno al pasado dictatorial. (p. 3)

Baste citar, para comprobar cómo el corpus constituido por las obras de los "hijos" está adquiriendo un espesor de género, las novelas siguientes, basadas en el recuerdo de infancia o de adolescencia durante la dictadura : Historia del llanto (2007) e Historia del pelo (2010) de Alan Pauls, Los topos (2008) de Félix Bruzzone, Glaxo (2009) de Hernán Ronsino, Soy un bravo piloto de la nueva China (2011) de Ernesto Semán, Una misma noche (2012) de Leopoldo Brizuela, Los cuervos de la memoria (2013) de Tabita Peralta Lugones, Una muchacha muy bella (2013) de Julián López, así como los relatos en francés de Laura Alcoba, Manège (2007) y Le bleu des abeilles (2013)... El género se extiende a las obras 
cinematográficas con películas como Los rubios (2003) de Albertina Carri, Andrés no quiere dormir la siesta (2009) de Daniel Bustamante, Infancia clandestina (2012) de Benjamín Ávila, El premio (2013) de Paula Markovitch...

En esta exposición, delinearemos algunos planteamientos básicos antes de interesarnos por Una misma noche de Leopoldo Brizuela que representa una manifestación interesante del género.

\section{Representaciones del espanto}

6 El terrorismo de Estado altera la identidad y compromete luego, por su carácter violentísimo, la cura posterior y la objetivación memorial del trauma. Del punto de vista de la representación, cuando se estudia con cierta distancia panorámica el conjunto de obras escritas en Argentina desde mediados de los '70, se ha de notar, como lo señala Saban, que las interpretaciones estéticas de tales hechos van cambiando con el paso de las generaciones.

7 En textos como los de Soriano, Piglia, Moyano, Costantini, Feinman y Bonasso era posible estudiar la narración, concebida como una construcción formal, aplicándole las abstracciones descontextualizadas de la teoría narratológica. Se podían así determinar las alteraciones padecidas por la voz narrativa (silencio, fragmentación, aislamiento) y el grado de realismo o de mediación metafórica con el que se transcribía la cruda realidad.

8 Mas, a partir de obras como Estrella distante (1996) de Roberto Bolaño, la relación entre la representación literaria y los hechos históricos se complica con la aparición de textos en los que los elementos biográficos, alterados por la identidad ambigua del relator, expresan una posición difícil de definir en el eje realismo/metáfora. Finalmente, con la generación de H.I.J.O.S, ese deslizamiento desemboca en una autoficción que asocia la experiencia íntima a la experiencia social, fútiles preocupaciones egotistas a pesadas realidades históricas.

Para aclarar en qué medida la autoficción enfocada en el horror dictatorial manifiesta un dispositivo particular -que tiene poco que ver con la crisis del "yo" que ha caracterizado algunas de las pioneras autoficciones francesas- quisiéramos recordar una opinión de los jueces de Eichmann referida por Hannah Arendt :

[...] ils dirent explicitement que des souffrances à ce point incommensurables étaient "au-delà de la compréhension humaine", qu'elles étaient l'affaire "des grands écrivains et poètes" et ne relevaient pas d'un tribunal, alors que les actes et mobiles qui en était la cause n'étaient au-delà ni de la compréhension ni du jugement. (p. 1222)

10 Los jueces distinguen los efectos de las causas. Estas entran en la competencia de la justicia mientras aquellos no pueden ser representados sino por los artistas. Se distingue así el trabajo de la justicia, basado en el análisis de los motivos y de los medios criminales, del quehacer artístico, solo capaz de medir en la víctima las consecuencias del crimen. Si son los artistas -no los jueces- quienes pueden alcanzar una forma de comprensión del sufrimiento, es porque disponen de los medios simbólicos y de las mediaciones estéticas para sublimar el espanto. En fin de cuentas, lo que los jueces exponen, es el problema de la observación, del cual deriva el problema de la representación : se puede mirar de frente al criminal sentado ante el tribunal, con toda objetividad; no se puede mirar de frente a la víctima torturada. 
11 Arendt aclara luego, al recordar la emoción que produjo en el público del proceso de Eichmann el testimonio de una víctima, Zindel Grynszpan :

Le récit de cette histoire ne dura peut-être pas plus que dix minutes et quand il fut terminé [...] on se disait bêtement: chacun, oui, chacun a droit à sa journée au tribunal. Mais c'était pour découvrir ensuite, au fur et à mesure de la succession interminable des audiences, à quel point il était difficile de raconter l'histoire, qu'il fallait - du moins hors du domaine de la transposition poétique - une pureté d'âme, une innocence de cœur et d'esprit irréfléchie et sans complaisance que seuls les justes possèdent. (p. 1240)

12 Parece que solo "la transposición poética" o "la inocencia" permitan relatar el espanto. Pero no todos aceptan renunciar a la objetividad documental para representar la experiencia de la víctima. Al respecto, si Albertina Carri coincide con los jueces israelíes al emplear en su documental, Los rubios, los recursos mediadores de la autoficción, los miembros del Comité de preclasificación del INCAA -solicitados por la cineasta para obtener una ayuda- echan al contrario de menos la ausencia de punto de vista objetivo en el proyecto. Su respuesta a Carri, leída en una escena de la película, reza lo siguiente :

El Comité [...] decide no expedirse en esta instancia sobre el proyecto titulado Los rubios [...]. Las razones son las siguientes : este proyecto es válido y pide en este sentido ser revisado con un mayor rigor documental. La historia tal como está formulada plantea el conflicto de ficcionalizar la propia experiencia cuando el dolor puede nublar la interpretación de hechos lacerantes. (00:25:54)

Los miembros del Comité apelan al "rigor" y no admiten la posibilidad de "ficcionalizar" hechos auténticos, tal vez porque temen que se frivolice la denuncia del crimen. Detrás se bosqueja una actitud ética : el crimen es demasiado serio para estar jugando, como lo hace Carri, con playmobils (la cineasta utiliza los populares muñequitos para representar el momento del secuestro). Las víctimas exigen respeto. La ficción las traiciona al tergiversar la realidad bruta con modalidades derivadas de la invención, del simulacro y, peor aún, del juego infantil. Si llevamos esta argumentación a sus últimas consecuencias, la única expresión legítima sería la que recoge el testimonio sin "transposición poética". Así hace en 2007 Nicolás Prividera en $m$, documental de aspecto clásico en el que el autor indaga el pasado de su madre desaparecida, Marta Sierra, mediante entrevistas a testigos del pasado. Mas, en el encuentro entre generaciones no siempre se logra, a pesar del método no ficcional, encontrar verdades y certidumbres sólidas. Ello revela no tanto los estragos del olvido sino la ambigüedad intrínseca de ciertas realidades y el hecho de que los testigos también construyen su propia ficción, frustrando la posibilidad de una transcripción verídica.

Otra respuesta al dilema la aportan los museos de la memoria. Los debates sobre estas experiencias, tal como los recogió $\tilde{N}$, manifiestan la pugna entre diferentes sectores por controlar la memoria. En relación con la oposición entre transposición poética y transcripción literal, a la pregunta “¿se corrió el riesgo de que se le imputara al Museo cierta tendencia estetizante de la historia ?", Rubén Chababo, ex director del Museo de la Memoria de Rosario, contesta :

El arte [...] emplaza al dogma y a las visiones cerradas y maniqueas, les pone un límite. Pero no faltaron los que lo visualizaron como un modo de no asumir un perfil militante o reivindicativo de las generaciones pasadas. Estas voces no lograron imponer, por suerte, su visión literal del pasado. Las visiones épicas son tranquilizadoras y ofician como consuelo para sobrevivientes y protagonistas que desean verse ocupando en el pasado el lugar "justo", pero eso a menudo se da de bruces con la incómoda verdad que devuelven los documentos de la Historia. 
Lo que está entredicho en esta respuesta es la voluntad, por parte de un sector del oficialismo de entonces, de fijar una interpretación de la victimización en torno a una épica del compromiso político tal como fueron encarados por grupos como Montoneros. Más explícita, la historiadora Mirta Zaida Lobato escribe :

Los gobiernos de Néstor y Cristina Kirchner jugaron un papel importante en el pasaje de la figura de la víctima a la del militante pues enunciaron y autorizaron una mirada a-crítica de los años previos al golpe de Estado de 1976, y tranquilizadora respecto de las responsabilidades de los grupos políticos que habían optado por las "armas".

Se entiende pues -cualquiera sea la opinión sobre el papel del kirchnerismo en el asuntoque el problema de la representación de la violencia dictatorial se complica, no solo por la oposición entre transposición poética y transcripción literal, sino también por los intereses divergentes entre los grupos que se disputan la conformación de la memoria dominante. Mas, si no queremos silenciar la importancia de dichos fenómenos, estos merecen una metodología (histórica, sociológica, etc.) ajena a nuestra espacialidad para poder ser considerados en el marco de este estudio.

Nos conformaremos pues con evocar la oposición entre transposición poética y transcripción literal. Desde ese punto de vista ¿cuál es la vía de mayor efectividad para representar la victimización? ¿La que preconizan indirectamente Arendt y los jueces de Eichmann o la que sostiene el INCAA ? Observemos que muchos escritores y cineastas han optado por la transposición poética. Eligiendo la reconfiguración ficcional para expresar el espanto, al mismo tiempo que filtran el horror (Carri que usa playmobils, Ávila el dibujo fijo del cómic en Infancia clandestina...), han creado un "yo" de laboratorio que se sustituye al "yo" autobiográfico. Para recalcar esa elección de la ficción, Félix Bruzzone, hijo de desaparecidos y autor de Los topos, ha declarado a Carolina Arenes y Astrid Pikielny : "[...] no tengo espíritu detectivesco. Es como si mi forma de llegar a esas cosas fuera más a través de la ficción que a través de investigaciones." (p. 33)

Lo cual no impide -y eso revela la sinuosidad de las estrategias de la memoria- que Bruzzone haya escrito también una carta a sus padres desaparecidos con datos reales y documentados en los que cuenta literalmente la tremenda suerte padecida por su padre, Félix Roque Giménez, en Campo de La Ribera (Córdoba).

\section{Autoficción por identificación ambigua}

Entre las exigencias del testimonio directo y las estéticas de la transposición poética, el artista (cineasta o escritor) enfrenta un dilema prácticamente insalvable. Tal vez la solución, a medio camino de las dos conminaciones, esté en la autoficción. La dictadura suscita así en los países del Cono Sur una narración particular del yo -construcción fictiva sutil, minuciosamente concertada en torno a hechos reales y colectivos conocidos por todos. Parodiando a Barthes, diríamos que esos relatos producen un efecto de autoficción sin ser autoficciones puras. Tal efecto proviene de la identificación entre el lector y el autor, favorecida por el hecho de que ambos comparten, sino una idéntica vivencia, por lo menos el recuerdo de lo que fue o de lo que pudo haber sido para cada uno. Por lo cual, el lector interpreta la historia relatada como una realidad experimentada, de una manera $u$ otra, por el autor cuando era niño. El efecto autoficcional tal vez sea difuso porque, como en el caso de la novela de Brizuela, puede no haber coincidencia suficiente entre el autor y el yo-protagonista ; o porque, como en la película de Ávila, el yo-protagonista no existe 
(no hay voz off por ejemplo, recurso que podría reflejar esa instancia desdoblando al protagonista en niño actante por un lado y en adulto narrador por otro), limitando lo autoficcional al juego de la identificación memorial entre la instancia productora y el espectador. Llamaremos ese tipo de relato autoficción por identificación ambigua. Lo definimos como una ficción en primera persona, ficción que transita entre las vertientes de un triángulo constituido por el receptor, el productor y el protagonista, siendo éste el foco ficticio en que se produce una identificación parcial y ambigua entre las personas reales (el receptor y el productor).

La construcción es compleja y establece una relación inestable con la realidad y la ficción, así como con las versiones convencionales de la autoficción y de la autobiografía, del testimonio y del informe. Le plantea al crítico el problema de saber cómo analizar una literatura que integra un carácter psíquico de ambiguo estatuto real, que se proyecta en una tela de fondo histórica y colectiva y que recupera la dimensión personal y subjetiva de una narración que ya no se puede estudiar como una pura función narratológica.

¿Qué justifica la elaboración de una autoficción tan peculiar y compleja? La respuesta radica en la conformación misma de la catástrofe social que provoca el trauma y determina luego las estrategias de la cura autoficcional.

En 2002, en un encuentro de psicoanalistas argentinos, se han explorado los efectos psíquicos de las catástrofes sociales. Bajo dicha denominación se incluían la represión de la dictadura, el atentado al AMIA y la crisis del modelo neoliberal que estalló en diciembre de 2001. Algunas de las reflexiones siguientes han sido inspiradas por ese trabajo.

\section{Catástrofe y devastación}

Sin descartar los accidentes debidos a las crisis neuróticas y a su terapia, Freud ha demostrado que el desarrollo psíquico individual se construye -a partir del complejo de Edipo y de otros elementos originarios-, mediante un sistema regulado, continuo y previsible. Cuando interviene la catástrofe, el sistema se abre al influjo exterior, se fragmenta, entra en un proceso de evolución complejo e imprevisible. Acerca de ese proceso de desarticulación, Silvia Bleichmar se plantea la pregunta siguiente :

Una vez constituido el yo [...], una vez constituidos los sistemas de significación que posibilitan más o menos la estabilidad del sujeto, qué ocurre cuando la incidencia de la realidad hace estallar estas formas habituales, y comienza a desarticular sus modos usuales de funcionamiento, a poner en jaque la relación del sujeto consigo mismo y con la realidad en torno. (p. 39)

Cuando eso ocurre, el individuo padece devastación. Tanto sus representaciones de la seguridad física y anímica (lo que Bleichmar llama autoconservación) como las de la identidad personal y social (autopreservación) son desmanteladas y entran en conflicto :

El caso más extremo de la contradicción entre autopreservación y autoconservación lo han marcado las situaciones históricas de terror, en las cuales muchos seres humanos han tenido que elegir entre vivir a costa de renunciar a los enunciados de base que los constituyen, o morir para poder seguir siendo quienes eran en tanto sujetos simbólicos [...]. (p. 42)

El individuo inerme y devastado se enfrenta a la dificultad de conseguir la respuesta simbólica que lo reconstruya, dificultad aumentada porque los discursos que circulan en la sociedad bajo el influjo de la palabra autoritaria devastan también el idioma y vacían de sentido los conceptos que podrían haber favorecido la representación de la catástrofe. Así 
ocurre por ejemplo con los discursos sobre la "guerra sucia", "los dos demonios", el "flagelo subversivo", que naturalizan la catástrofe ; así también con las expresiones "el ilícito", "los argentinos somos derechos y humanos", "en algo estaban metidos" que desemantizan la crítica y la denuncia del crimen.

Escriben los compiladores de Clínica psicoanalítica ante las catástrofes: "Si alguna palabra refleja el efecto que en la subjetividad colectiva y en la subjetividad individual genera el fenómeno de la catástrofe social, esta palabra es devastación." (p. 29) Este proceso psicológico establece una relación entre la explosión catastrófica y las etapas biográficas siguientes en que explota también, en el peor de los casos, lo reprimido o en que el sujeto arma, en el mejor de los casos, las estrategias de la reconstrucción. Así se constituye un diálogo entre el pasado como momento de estallido de la catástrofe y el presente como actualización de esa crisis e intento de resolverla. El narrador de La casa operativa de Cristina Feijóo extrema aún dicha manifestación del pasado al declarar que no existe una cronología que dividiera el tiempo en remoto y actual sino un sistema continuo que hace que todo, en la mente, sea simultáneo :

Siendo chico descubrí que dentro de mí existen focos de energía que condensan la memoria. Hoyos potentes en las profundidades del cerebro, y en ellos bombas, aún activas. Las situaciones que originaron estos cuásares no forman parte del pasado ; su energía no se consumió. Son situaciones que se agitan y centellean en zonas ocultas; no mueren. Integran un presente continuo que se reproduce, se disfraza, se clona para alimentarse. Me come. Me chupa la sangre. (p. 11)

Pero tal vez el "yo" narrativo de la novela de Feijóo encubra en estas líneas un problema mayor : el hecho de que la devastación y la reconstrucción subsiguiente no solo suponen abrir el continuo individual a un flujo de presiones exteriores alienantes, sino abrirlo al campo colectivo en el que interactúan otros individuos, ya que la catástrofe no es únicamente individual: es también social, política, histórica. De ahí la necesidad de articular justamente lo que los psicoanalistas citados llaman la subjetividad individual y la subjetividad colectiva, como dos escalas conectadas entre las cuales los sentidos se transfieren. En su documental $m$, Nicolás Prividera dice a propósito de su trabajo de investigación y de la dificultad de conectar esas escalas :

Lamentablemente hay que activarlo al nivel personal ¿no ? [...] cada uno tiene que ir con su caso particular cuando la represión fue generalizada, fue sobre el cuerpo social. Bueno... pero lo que nos queda es : cada uno, desde su lugar, intentar saber algo más. (05:51)

En relación con todo ello, ¿qué significa, treinta o cuarenta años después de los hechos, dedicar una obra al problema de la devastación social provocada por la dictadura? Recordemos una obviedad, indirectamente registrada por Prividera en la cita anterior y por Arendt con el caso de Grynszpan: fuera de las estadísticas desencarnadas y de las macro-visiones socio-económicas, nuestra cultura no puede percibir la experiencia colectiva sin pasar por el testimonio individual. En los relatos estéticos, también la escala individual se antepone, por medio del protagonista, a la escala colectiva ; lo cual obliga a plantear el problema de la experiencia personal del creador mismo, como motivación principal del relato autoficcional. ¿Tendría sentido esta escala inicial e individual si el responsable del relato estético no estuviera implicado como sujeto único devastado que crea para reconstruirse? En el contexto particular de la catástrofe política es difícil componer una obra que apuntara a la reconstrucción del Otro o del Nosotros sin pasar por la del Yo. Esta implicación personal del artista nos hace caer pues en obras que, después de la muerte del sujeto biográfico que caracterizó la literatura de los ' 60 y '70, lo 
resucita según la forma de la autobiografía más o menos real o de la autoficción por identificación ambigua.

En 1980, Piglia escribía que no había más aventuras, que solo quedaban parodias. Así formulaba, en una época en que la experiencia de 30.000 argentinos había terminado en la aniquilación, la dificultad de recoger esa experiencia en términos de peripecia épica. Faltaba encontrar la fórmula que permitiera una proyección y una reconstrucción futura. Pensamos que a partir del 2000 se da esa posibilidad con el cambio de generación que le permite a un adulto de hoy recordar su infancia o su adolescencia bajo dictadura. Estos relatos introducen una nueva dimensión en la percepción de la catástrofe : las víctimas ya no son adultos implicados en una elección responsable ante el conflicto, sino niños que no llegaron a entender gran cosa cuando ocurría la catástrofe que los afectaba, a ellos y a sus padres, y que, una vez mayores, tienen que regresar al pasado para comprenderlo desde una mirada transitiva, que circula entre adultez y niñez, individualidad y sociedad, enfrentando el abismo de los sufrimientos, del espanto y de los errores de la generación anterior. Como prólogo a su trabajo de recopilación testimonial, escriben Arenes y Pikielny :

La pregunta sobre el vínculo de esos hijos con sus padres encierra una clave que es singular [...] pero que remite también a la clave más amplia de la memoria social. Historias mínimas de una historia nacional que aún produce "un pasado que duele" [...]. (p. 9)

\section{Niño de antaño y adulto de hoy}

En muchos casos, la presencia del adulto como instancia mediadora y narradora actual está explicitada por las características de la narración, como en Una misma noche de Brizuela o Manèges de Alcoba. En otros, se plantea como una hipótesis : por ejemplo, en la película de Benjamín Ávila, Infancia clandestina, la instancia productora es anónima pero no podría elaborar la trama del relato si no contara con los efectos de la aproximación mnemónica colectiva por los que, tanto los espectadores como los autores, regresan a la realidad de una infancia durante los 70'. Además, la dedicatoria final, "A Sara E. Zermoglio, madre desaparecida el 13 de octubre de 1979", así como las fotos que acompañan los títulos de crédito introducen el espesor real de una historia familiar concreta.

31 En cuanto a la distancia entre el niño y el adulto, se manifiesta mediante la manera en que el narrador focaliza de manera más o menos intrusiva la experiencia pasada. En Soy un bravo piloto de la nueva China de Ernesto Semán, el narrador adulto compensa la ignorancia del niño que fue antaño mediante el fantasma y la imaginación; en Una muchacha muy bella de Julián López, intenta no aportar a su descripción de la experiencia infantil lo que aprendió luego como adulto ; en Manèges de Laura Alcoba, reproduce con suma fidelidad no sólo la experiencia sino también la lógica y la sintaxis infantil ; en Una misma noche de Leopoldo Brizuela, se entromete en todo, estableciendo una fuerte continuidad de identidad entre él y el niño que revela su inmadurez; en La casa operativa, se desdobla en primera y tercera persona, señalando la dificultad por determinar la relación exacta entre el niño y el adulto : "De a ráfagas, mi madre está aquí, está su olor y su voz. También está ese chico [...], que ya no soy, del cual soy un testigo." (p. 29) 

y adultez tiene mucho valor el trabajo de Saban que escribe a propósito de la novela de Alcoba :

La novela transforma la historia en algo comunicable mediante una serie de recursos, el más importante de los cuales es la superposición de dos niveles narrativos: la narración diegética del pasado y la reconstrucción del recuerdo desde el presente. En un primer momento, el acento parece estar puesto en los acontecimientos vividos por la niña en el pasado y el tiempo se narra, por lo tanto, en forma cronológica. La focalización interna en la experiencia infantil subraya la inmediatez episódica de lo que se cuenta, de tal modo que la autenticidad del recuerdo emerge en un primer plano. Pero ese tiempo ingrato de las reminiscencias queda integrado en el proceso del recuerdo, dominado por la narradora adulta que funda su identidad mientras reflexiona sobre su propio yo. (p. 170)

Como lo señala Saban, en esta novela como en otras muchas del corpus el relato establece dos focos productivos : el niño-potagonista de antaño y el adulto-narrador de hoy, ambos asociados a través del tiempo por las nociones de reminiscencia, de estallido de una experiencia traumática que muchos años después origina una escritura como terapia y como reconstrucción.

La reconstrucción del recuerdo, ya sea fictivo (en Historia del llanto de Alan Pauls por ejemplo) ya sea real (en Manèges de Laura Alcoba), es el disparador de un movimiento circular que relaciona la escritura a la catástrofe original y que permite a la experiencia particular, aislada, del niño proyectarse en la colectividad de los lectores y de las otras experiencias expresadas en otros relatos, en informes y testimonios. Es decir que el relato como terapia no tiene sólo un alcance individual y remoto, sino también colectivo y presente porque participa en una intertextualidad de los testimonios históricos actualizados en una perspectiva de comprensión del "yo" y del "nosotros" actuales.

\section{Una misma noche, Leopoldo Brizuela}

Si a largo plazo nos proponemos analizar varias obras de este corpus para evaluar sus convenciones genéricas, nos conformaremos por ahora con explorar algunos aspectos de la novela de Brizuela, Una misma noche, cuyo narrador protagonista decide -en 2010regresar a los años 74-77 mediante un cuaderno de bitácora en el que junta documentación periodística y bosquejos literarios. El pasado reconstruido se actualiza pues en el presente de la escritura con el surgimiento, en la conciencia del relator adulto, de la dimensión colectiva de la catástrofe de la cual el niño había padecido una versión doméstica. Además, si el narrador se llama Bazán y el autor verdadero Brizuela, ambos comparten ciertos rasgos que sugieren un difuso vínculo autoficcional, como la fecha de nacimiento (1963) y el oficio (escritor). El relato se impone pues como un testimonio personal, fundido en lo real y arraigado en una memoria concreta fácilmente reconocible en términos de generación.

La novela se divide en cuatro partes cuyos títulos explicitan diferentes modos de representación del pasado :

-(1) la ficcionalización, "Novela" (p. 11-87);

-(2) el recuerdo subjetivo, "Memoria" (p. 89-155);

-(3) la referencia histórica, "Historia” (p. 157-242);

-(4) la transposición fantasmática, “Sueño” (p. 243-272). 

prestar el patio de su casa a los represores para que pudieran entrar en la casa de los Carri y secuestrarlos. Sabemos que la novela de Brizuela cuenta una historia semejante, pero con un cambio de ángulo narrativo ya que en su relato la instancia productora extradiegética no concuerda con la hija de los desparecidos, como en Los rubios, sino con el hijo del vecino, transformado en cómplice involuntario de los militares. Por tanto, si se acepta la idea de una intertextualidad entre la película de 2003 y la novela de 2012, las semejanzas entre los personajes de la ficción y las personas reales se presentan como perfectamente intencionales. Así, con la referencia a lo que fue o a lo que pudo haber sido se establece la autoficción por identificación ambigua, la cual se verifica gracias al sentido académico de la palabra "coincidencia" empleada en el colofón. 
experiencias atestiguadas en informes, en documentales (como el de Carri), en testimonios recogidos por el periodismo o por los procesos judiciales.

El dispositivo de identificación supone poner en movimiento el intercambio entre el pasado y el presente, ambos semantizados tanto por la experiencia individual como por la colectiva, la experiencia de Bazán-Brizuela y la de cada lector proyectándose en los debates nacionales actuales -judiciales y políticos- con los que se pretenden resolver los crímenes del pasado.

\section{Conclusión}

Antes de acabar esta exposición, quisiéramos evocar, ya no los problemas generales de ficcionalidad y de realidad, sino los hechos particulares que conforman en Una misma noche la trama transitiva entre pasado y presente.

El trauma pasado estalla a modo de regreso de lo reprimido cuando Bazán, el protagonista, se entera que ha habido en su barrio una serie de asaltos que le recuerdan las violaciones de domicilio cometidas por los grupos de tarea y el secuestro de su vecina, Diana Kuperman, durante la dictadura. La actualización se proyecta en la realidad social y colectiva por el hecho de que Diana estaba relacionada con el caso de Papel Prensa, tema de discordia muy actual entre Clarín y el gobierno de Cristina Fernández. Por fin, la complicidad de su padre en el rapto de Diana acaba por conformar el síndrome traumático que impulsa a Bazán a escribir.

Bazán pues no es un Hijo con mayúscula, es decir un hijo de víctima, sino un hijo de cómplice. Su trauma consiste en resolver el profundo sentimiento de culpa transmitido por herencia. De ahí su impresión de ser un impostor de la memoria cuando visita por ejemplo la ESMA o cuando intenta comunicarse de nuevo con su vecina sobreviviente.

El sentimiento de culpa revela sus terribles efectos en los dos últimos capítulos, el Y y el Z, en que el narrador retrocede hasta 1974, un tiempo de su infancia anterior a la triste noche en que asistió a la transformación de su padre en verdugo. Recuerda su zambullido en la piscina de la vecina y expresa su voluntad de no salir, de ahogarse o por lo menos de representarse a sí mismo un simulacro de ahogo :

Doy un salto. Me tiro a la pileta ;

Ah, dentro del agua, el tiempo se diluye y yo mismo me diluyo.

[...] Me hundo un poco más, hasta llegar al fondo.

Ya casi no resisto. Pero quiero saber que puedo resistir. Cómo es no poder más.

Cierro los ojos y veo el fondo espléndido, el centro de la tierra, su negrura. (p. 271)

Luego viene la página negra del capítulo Z (p. 272), negra como una representación de la muerte que el adulto hubiera preferido experimentar para no asistir luego al crimen de su padre. La escena recordada o imaginada en 2010 por Bazán adulto, que se sitúa en 1974 e involucra a Bazán niño, expresa pues una forma de culpabilidad por anticipación. Tal vez exprese también la identificación con las víctimas al evocar un simulacro de ahogo tormento empleado por los represores- $\mathrm{y}$ al desembocar en la negra página 272 , metáfora tal vez de los chupaderos y de la desaparición. 


\section{BIBLIOGRAFÍA}

Alcoba, Laura, Manèges. Petite histoire argentine, Paris : Gallimard, 2007

Arendt, Hannah, Les origines du totalitarisme. Eichmann à Jérusalem ; ed. de Pierre Bouretz ; trad. al francés de M. Pouteau, M. Leiris, J.-L. Bourget, R. Davreu, P. Lévy, A. Guérin y M. I. Brudny de Launay, Paris : Quarto Gallimard, 2002

Arenes, Carolina y Astrid Pikielny, Hijos de los 70. Historias de la generación que heredó la tragedia argentina, Buenos Aires : Sudamericana, 2016

Brizuela, Leopoldo, Una misma noche, Madrid : Alfaguara, 2012

Bruzzone, Félix, "40 años del golpe. Paciencia de tenedores y cucharas”, Revista Anfibia, universidad Nacional de San Martín. Consultado el 26/07/2016 en : http:// www.revistaanfibia.com/cronica/paciencia-de-tenedores-y-cucharas/

Bruzzone, Félix y Máximo Badaró, “Hijos de represores : 30 mil quilombos”, Revista Anfibia, universidad Nacional de San Martín. Consultado el 03/08/2016 en : http:// www.revistaanfibia.com/cronica/hijos-de-represores-30-mil-quilombos/

Carri Albertina, Los rubios, 2003 (http://www.cinemargentino.com/films/914988608-los-rubios)

Clínica psicoanalítica ante las catástrofes sociales. La experiencia argentina, Daniel Waisbrot et al. (comp.), Buenos Aires : Paidós, 2003

Feijóo, Cristina, La casa operativa, Buenos Aires : Planeta, 2007

Genette, Gérard, Fiction et diction, Paris : Seuil, 1991

Grell, Isabelle, L'autofiction, Paris : Armand Colin, 2014

Prividera Nicolás, m, 2007 (http://www.cinemargentino.com/films/914988720-m)

Saban, Karen, Imaginar el pasado, Heidelberg : Universitätsverlag Winter, 2013

\section{RESÚMENES}

Con la llegada en el campo literario y cinematográfico de la generación de HIJOS, ha ido emergiendo en los relatos argentinos que contemplan la época de la dictadura un nuevo paradigma de creación centrado en la memoria de infancia. Actualmente, el corpus representado por esas obras alcanza una proporción suficiente para constituir un género propio, con sus convenciones, sus normas y sus modelos.

Después de caracterizar los problemas estéticos y éticos planteados por dicho género, examinaremos Una misma noche (2012) de Leopoldo Brizuela, novela particularmente representativa del corpus.

Avec l'arrivée dans le champ littéraire et cinématographique de la génération de HIJOS, un nouveau paradigme de création centré sur la mémoire d'enfance a émergé dans les récits argentins qui se penchent sur l'époque de la dictature. Aujourd'hui, le corpus représenté par ces œuvres atteint une proportion suffisante pour constituer un genre propre, avec ses conventions, ses normes et ses modèles. 
Après avoir déterminé les problèmes esthétiques et éthiques posés par ce genre, nous étudierons Una misma noche (2012) de Leopoldo Brizuela, roman particulièrement représentatif du corpus.

The appearance of the HIJOS generation in the literary and cinematic fields has generated a new, creative paradigm centered on memories of childhood in Argentine tales about dictatorship. Today this corpus amounts to a sufficient number of works to constitute a proper genre endowed with specific conventions, norms and models.

This paper will seek to determine the aesthetic and ethical problems relevant to the genre, before focusing on a particularly representative work - Leopoldo Brizuela's Una misma noche (2012).

ÍNDICE

Mots-clés: autofiction, catastrophe, Brizuela (Leopoldo), dictature, HIJOS, enfance, littérature argentine (XXe-XXIe siècles), mémoire

Palabras claves: autoficción, catástrofe, Brizuela (Leopoldo), dictadura, HIJOS, infancia, literatura argentina (siglos XX-XXI), memoria

Keywords: autofiction, catastrophe, Brizuela (Leopoldo), dictatorship, HIJOS, childhood, Argentine literature (19th - 20th c.), memory

\section{AUTOR}

JOSÉ GARCÍA-ROMEU 